\title{
Constraints in Urban Housing Planning and Control: A stakeholders' perceptions
}

\author{
Hamizah Yakob, Fatimah Yusof, Hazlina Hamdan \\ Faculty of Architecture, Planning and Surveying, \\ Universiti Teknologi MARA, Shah Alam, 40450, Malaysia \\ hamizah1204@gmail.com
}

\begin{abstract}
Planning mechanism such as development plan and planning control are consider to be some of the contributing factors in achieving successful housing development mainly in urban areas. However, the effectiveness of housing planning and control is still questionable especially when there are matters related to housing oversupply, a housing shortage, and housing quality. The objective of this paper is to outline the perception of housing planning and control among stakeholders on three elements; housing policies, development strategies and procedures for housing planning applications. The analysis indicate that the effectiveness of these elements being implemented could ensure successful future housing development.
\end{abstract}

Keywords: Housing policies; development strategies; procedures for housing application; stakeholders

eISSN: 2398-4295 (C) 2016. The Authors. Published for AMER ABRA by e-International Publishing House, Ltd., UK.. This is an open access article under the CC BY-NC-ND license (http://creativecommons.org/licenses/by-ncnd/4.0/). Peer-review under responsibility of AMER (Association of Malaysian Environment-Behaviour Researchers), ABRA (Association of Behavioural Researchers on Asians) and cE-Bs (Centre for EnvironmentBehaviour Studies), Faculty of Architecture, Planning \& Surveying, Universiti Teknologi MARA, Malaysia.

https://doi.org/10.21834/ajbes.v1i3.36 


\subsection{Introduction}

Planning system plays an important role in the housing development process. Its mechanism includes development plans and implementation of planning control which could influence the existence of new housing developments. The housing policies outlined in the development plan are used as a guide and tool during the development control process, where each housing application is assessed and evaluated by the local planning authorities for approval. An effective housing planning practice can control the development of land use and consequently overcome the issues pertaining to housing mainly in urban areas. Planners have always been considered to play an important role in housing planning such as formulation of housing policies and guidelines, however, it is important to note that housing developers have also been able to influence and shape the urban housing development (Othman, 2006).

Even though housing planning and control are used as a tool and guidelines that need to be complied with, planning problems and constraints affecting them, particularly in dealing with the application of planning permission have some impacts on the urban living environment. It is widely believed that housing issues can be exacerbated by the ineffectiveness of housing planning and control process. There are various arguments pointing out that the main cause of housing problems is due to weaknesses and ineffectiveness of housing planning process (Othman, 2006; Rameli, 2009; Mohd, 2011). Thus, this paper attempts to look into key stakeholders' understanding on the effectiveness of housing planning and control which reflects their roles in decision making for urban housing development. The objective of this paper is to outline the perception on housing planning issues related to development plan implementation aspects; firstly on the effectiveness of policies and development strategies in Structure Plan (SP) and Local Plan (LP) and secondly on problems in relation to procedures for housing planning application

\subsection{Literature Review}

\subsection{Land use planning and control in housing development}

Generally, land use planning deals with several systems that influence the physical structure of the urban area which are activity system, land development systems and environmental system (Chapin \& Kaiser in Rameli, 2009). The activity system is concerned with how man fulfils their needs, which consequently leads to demand for various urban spaces including housing. By using the activity systems, the urban space is converted and adapted to the needs of the population, a process that involves stakeholders such as developers and consumers in the process of land development systems; whilst environment systems function both to control and to develop the functioning of the other two systems stated. In relation to housing, the land use planning system plays an important role in the housing development process to achieve the social, physical and economic goals by 
providing sufficient housing (Golland, 2004), encouraging sustainable housing development and ensuring an efficient housing delivery system. All these objectives can only be achieved with the implementation of urban planning and guidance system through planning and political activities (Rameli, 2009 \& Preerapun, 2012).

Meanwhile, Shirotsuki, Otsuki, Sonoda, \& Centre, (2010) claimed that government intervention in the preparation and formulation of the planning policy could control housing developments. Jiboye, (2011) and Yakob, Yusof, \& Hamdan, (2012) in their study emphasise the need for good governance through the application of development strategies for effective housing delivery. They claimed that housing policies and commitment among stakeholders are crucial to ensure sustainable housing delivery system. In addition, Rameli, (2011) indicated that planning mechanisms have much influence in the Malaysian housing planning process. Housing policies and strategies outlines in the SP and LPs will be used as a guide and basis in considering any housing development applications during the development control stage. This is supported by Othman, (2006) who found that planning is a major factor in ensuring successful housing development. The role of the government in making rules and regulations, preparing development plans and planning standard and guidelines could affect housing development as a whole and consequently determine housing supply. Weaknesses at control and approval development stages could result in property overhang and oversupply (Bramley, 2003; Aluko, 2011).

\subsection{Housing planning activities in development plan and control}

In Malaysia, housing planning activities are influenced by the development plans and implementation of planning control. As provided in Act 172, various development plans including SP and LPs have been formulated in order to guide the decision makers or planners when processing planning permissions (Abdullah \& Rahman, 2011). In carrying out housing studies during the preparation of development plans, planners are required to consider several activities, scope and aspects based on Manual. The activities include a survey of existing housing condition, projection of housing requirement and formulation of housing policies. In relation to housing policies outlined in the SP, the factors to be considered are mainly concentrated on low cost and affordable housing, fulfilling housing needs, location suitability and availability of land area (Mohd, 2011). The effectiveness of housing policies implemented and translated to other plan is important and will consequently facilitate the process of planning control (Choguill, 2007). Meanwhile, in LPs, the development strategies outlined which are determinations of housing land location and distribution of total land size for housing are the two main aspects that are important to measure the effectiveness of housing planning (Rameli,2011). Availability of land adjacent to existing housing development, good accessibility from the main road and avoiding housing developments in restricted areas are among aspects considered in distributing land location for housing during the preparation of a LP. In addition, the determination of land area should also consider other planning requirements such as provision of open space, community facilities and utilities to create a better living environment. Planning permission 
procedures is another aspect in considering the effectiveness of housing planning which achieves planning control through compliance to guidelines, zoning and other planning requirements (Hassan, Bakar, Ramli, Jamaludin \& Adamy, 2010; Wu \& Cho,2007).

\subsection{Past researches on housing planning and control}

However, based on previous studies, there are issues and problems in housing planning related to the three planning aspects highlighted. Major issues in the process of planning application as revealed by Othman (2006) and Chua \& Deguchi, (2008) indicated that even though planning serves as a basic tool to guide housing direction, developers have to deal with problems of uncertainty in the rules and procedures, changing rules, regulations and requirement which could lead to non-compliance. This might be due to poor contents of LP, delays and management problems. With regards to policies, Rameli (2011) argued that even though planning has its roles in the housing production process, failures in the housing market seems to be happening due to the unresponsiveness of the planning system. He claimed that the operation of the planning system should fulfil both the housing needs and housing demands so that the policies are effectively implemented by developers as the main provider of housing. Meanwhile, Mohd (2009) argued that the planning systems constrained the efficiency of housing development; restrict supply of housing land, location of housing, the type and density of development and the timing that the development could take place. Developer found the policies and concepts with regards to land location and size as the main cause of difficulties in housing development. They claimed that the land location should take into consideration the economic aspects such as availability of land, construction cost and demand. On the other hand, Rameli (2009) indicated that planning ensures order in the development by allocating sufficient land for future housing in accordance with actual need, demographic projection and household formation statistics. There is also an argument that the provision of open spaces and facilities could affect the number of housing units to be built because it causes difficulties in land dealings.

\subsection{Methodology}

The research undertakes a questionnaire survey involving the stakeholders for primary data. This pilot survey consists of two main key players involved in housing developments within Selangor. The respondents chosen are those listed as registered members of the Real Estate and Housing Developers Associations (REHDA) and the Malaysian Institute of Planners (MIP). Planners from the local planning authorities (LPAs) were also chosen as samples for the study. This pilot test was conducted within the Petaling District (in which the area falls under administration of MBSA, MBPJ and MPSJ). The study area is one of the significant economic nodes of the Klang Valley region with rapid and dynamic growth covering a number of land uses including housing sectors. The criteria for selection of the respondents are those involved in the housing planning applications and approvals. This 
study has its limitation. The sample size determine for the pilot survey is thirty respondents; however, due to constraints in terms of respondents willingness during data collection, only sixteen respondents samples were obtained (including nine planners and seven developers) using a convenience sampling method. The study proceeded with number of respondents and accepted all the weaknesses in findings due to the low number of respondents. However, as it is a preliminary survey, an identification of new direction for future research will be discussed in the conclusion. Face-to-face interviews were administered to ensure that the respondents fully understood the questions asked to them. The survey was conducted within a two month period (in June and July 2013) beginning from 9am to $5 \mathrm{pm}$ each day. Respondents those were not available during normal working hour were interviewed during weekends.

Even though there are debates in literatures concerning what constitute and how to measure effectiveness of housing planning systems, basically there are three main activities involved which are; forward planning, development control and implementation of particular development (Rameli, 2009). From these activities, planning factors in urban housing development can be viewed to comprise six aspects. The aspects are development plan, planning standard and guideline, planning application procedures, planning decision, planning communication and correspondence and non- planning factor (Mohd et al, 2007). These planning aspects are important as indicators in measuring the level of effectiveness of housing planning and control mainly in urban areas. With regards to housing planning and control, this paper concentrates on three main aspects of planning causing difficulties in housing applications and approvals which are; 1) housing policies, 2) development strategies and 3) planning application procedures. The assessment of the selected aspects indicates perception among stakeholders on housing planning and control in urban areas. The data gathered were statistically analysed using SPSS. Reliability test on the measurement were conducted for variables in one planning aspect- housing policies. The testing was conducted to check the consistency of all related factors in the study based on Cronbach Alpha's value. The Cronbach Alpha testing is use as it is the most well accepted reliability test tool applied by social researchers (Sekaran, 2009). The variable tested for the level of effectiveness in housing policies has a Cronbach Alpha value of 0.894 . Whenever applicable, Mann-Whitney U Test analysis are carried out for non-parametrical purposes to measure the correlation between two groups of respondents and the selected variables (level of effectiveness of housing policies, level of compliance and applicability in housing procedures). For other remaining variables such as planning requirements and housing land location, analysis was done descriptively for easy understanding and interpretation (Pallant, 2010). Frequency distributions and percentages are used for this purpose. 


\subsection{Results and Discussions}

\subsection{Housing policies}

The variable tested is level of effectiveness of housing policies formulated and outlined in the SP. Descriptively, most planners (100\%) seemed to agree that housing policies are effectively translated and implemented whilst $14.3 \%$ of housing developers claimed that it is ineffective. However, the Mann-Whitney $U$ Test shows that there is no significant difference ( $p>0.005)$ in the perception on the level of effectiveness between planners and developers based on the result of $z=-1.516$ with $p=0.129$. The mean rank score for planner $(10.00)$ is just slightly higher than developer (6.57) which suggested that the stakeholder's perception is not correlated with the level of effectiveness of housing policies. It indicates that the different perceptions are due to different needs by each group, whereby most planners formulate policies for public needs while developers much concerned with their economic needs.

Mohd et al (2007) claimed that housing policies outlined are sometimes difficult to implement on the ground. Problems claimed by housing developers are mostly related to compliance to low cost housing policies, provision of open space and facilities (Othman, 2006; Shuid, 2010; Moh et al, 2009; Zainal, Kaur, Ahmad \& Mohd, 2012). Based on the mean and standard deviation analysis on the perception of respondents on housing policy of "Fulfilling future housing needs" has the highest mean score (3.65). It was followed by "Determination of future housing development boundary based on suitable location and demand" and "Provision of public facilities and infrastructures in housing development areas" with the same mean score (3.50). Other policies are "Formulate, improve and enforce laws, regulations and guidelines for housing" (3.31), "Enhance service delivery through policy coordination" (3.31), "Set quality housing standard and use of material" (3.19) and "Development of low cost housing and encourage medium low cost housing" (3.06). Meanwhile, the result shows a lower mean score for housing policies related to housing price (2.75). This could be affected by ineffective implementation of laws and planning policies (Hui \& Ho, 2003).

\subsection{Development strategies}

The variables measured in terms of 1) perception towards size and quantity required for the provision of open space, facilities and infrastructure, and 2) the planning considerations involved in determining housing land location. For the first variable, the result shows that both respondent groups agree that size and quantity for provision of such planning requirements does not affect the number of houses built with the agreement of $55.6 \%$ of the planners and $42.9 \%$ of the developers involved in the study. However, $42.9 \%$ of developers disagreed with the statement. The number of developers disagreed and agreed is equivalent as this is opposed to Mohd et al, (2007) that pointed out the problems among housing developers complying with the planning standard for open spaces, facilities and 
infrastructure provision (quantity and size). The large land acreage required to provide community facilities limits the number of houses that can be build. Other factors are land price, shortage of land supply and development cost. From the planning perspective, such a requirement is compulsory and is a basic need for the urban population.

The multiple answer questions are used for the second variable. The result shows that "good accessibility from the main road" (93.75\%) is the most important aspect considered by both group of respondents in determining suitable housing location. This is followed by "land use zoning for housing" and also some consideration on "economic factors" such as demand and supply (75\% respectively). Factors such as "avoid from developing within the restricted area" and "availability of land adjacent to existing or surrounding housing development" (68.75\% respectively) are also considered in this survey questions. Moreover, determining a suitable land location for housing is one of the indicators to measure the level of effectiveness of housing planning (Rameli, 2011, Hashim, Samikon, Nasir \& Ismail, 2012). The effectiveness of these aspects could affect the housing supply and delivery system as a whole. Specifically, $44 \%$ of planners regarded all five aspects as important while $42.9 \%$ of the developers agreed that land for housing should be located within the proposed land use map. This is because; it is the most important part during the preparation of housing layout plan and approval by the LPAs.

\subsection{Housing application procedures}

Both groups of respondents agreed that housing application procedure does not comply with the provision of the SP and LP with the agreement of $55.5 \%$ of planners and $71.4 \%$ of developers involved in the study. This is in line with the legal provision in Section 18 of Act 172 which stated that 'no person shall use or is permitted to use any land or building other than in conformity with the $L P$ '. For the second variable, $100 \%$ of planners agreed that the development plan is a good, acceptable and applicable tool in guiding housing applications and approvals, whilst $14.3 \%$ of developers considered it as a bad tool. This variation is perhaps due to problems during application and approval which will be discussed at the end of this section. However, the result of Mann-Whitney $U$ Test shows that there is no significant difference $(p>0.05)$ in the perception on the level of compliance between planners and developers. Specifically, the result of the data analysis recorded $z=-0.492$ with $p=0.623$. The mean rank score for planners (8.94) is just slightly higher than the developers (7.93) which suggested that the stakeholder's perception does not correlate with the level of compliance. Similarly, for the next variable, the test results shows that $z=-1.768$ with $p=0.074$. Even though the mean rank value for planner (9.78) is higher than that of the developers (6.86), the result shows that there is no statistical significant in the difference between variables in the two respondent groups.

Multiple answer questions are used for this section which illustrates the respondents' perception on the problems they have faced during a housing application (for developer) and approval (for planner). The result shows that "compliance to low cost housing policies" $(75 \%)$ is the most common planning difficulties during housing application and approval. 
This is followed by "compliance to planning standard and guidelines" (68.75\%) such as density control, ration and types of development allowed, "compliance to Master Plan" and problems related to "preparing and gazetting period" (56.25\% respectively), "compliance to the proposed land use zoning" and "compliance according to priority area" (37.5\% respectively) and "technical errors in preparing proposal layout plan" (25\%). The causes of non-compliance claimed that a possible reason for a development not conforming to the development plan is related to its poor content. This has caused certain developments which have adopted non-conventional design, to experience difficulties in adjusting and meeting the requirements of LP especially related to density or plot ratio of a development. Overall, the assessment in the three planning dimensions for this study has demonstrated some views in measuring the effectiveness of housing planning in urban areas. By incorporating housing policies, strategies and planning procedures, it not only leads to improvements on the housing planning process but will also increase the role of planning system in providing sufficient housing, encouraging sustainable housing development and ensuring efficiency in the housing delivery system (Rameli, 2009; Mohit,2012).

\subsection{Conclusion}

This pilot survey intended to measure the effectiveness of housing planning and control through key stakeholders' perception before the actual study conducted. A pilot study also functions to identify potential problems that may arise in the actual study as well as to evaluate the suitability of the questions (Sakip, 2012). In the case of this pilot study, several problems have been identified in terms of the use of Likert scale and multiple choice questions (MCQs). It seemed to be difficult to interpret the data involving MCQ especially in obtaining facts from both groups. In addition, the sample size for this pilot survey is also smaller which might affect in the result of findings especially in analysing the significant differences between two groups based on the selected variables. The outcome of this paper is expected to be used as a supporting and fundamental data to carry along to the next level of the main research. In general, it was discovered that the use of questionnaire forms to identify the perception of both respondents towards effectiveness of housing planning and control components such as housing policies, development strategies and housing planning procedures was effective; however, the use of this scale of research involving sample size etc, need continuous development to enable it to be suitable for use in any related studies.

\section{Acknowledgement}

This research is funded by the Ministry of Education, Malaysia and Universiti Teknologi MARA. Also, special thanks to the respective respondents for all their cooperation in participating in this pilot survey. 


\section{References}

Abdullah, A. A. \& Rahman, H. A. (2011). Planning process of development project in the Malaysian context: A crucial brief overview. International Journal of Applied Science and Technology, 1(2), 74-81.

Aluko, O. (2011). The effects of land use act on sustainable housing provision in Nigeria: The Lagos state experience. Journal of Sustainable Development, 5(1), 114-122. doi:10.5539/jsd.v5n1p114

Bramley, G. (2003). Planning regulation and housing supply in a market system. In O'Sullivan, T \& Gibbs, K, Eds. Housing economics and public policy. United Kingdom: Blackwell Science Ltd.

Chua, R. S. \& Deguchi (2008). Implementation issues on planning control according to the provision of Town and Country Planning Act 1976 in Malaysia. Journal of Architecture and Urban Design, 47-58.

Choguill, C. L. (2007). The search for policies to support sustainable housing. Habitat International, 31(1), 143-49. doi:10.1016/j.habitatint.2006.12.001

Emmanuel, J. B. (2013). The quality of housing produced by the low income in a developing country : A case study in Ibadan, Nigeria. Asian Journal of Environment-Behaviour Studies, 4(11), 85-97.

Golland, A. \& Blake, R. (2004). Housing development: Theory, process and practice. London :Routledge.

Hashim, A. E., Samikon, S. A., Nasir, N. M. \& Ismail, N. (2012). Assessing factors influencing performance of Malaysian low-cost public housing in sustainable environment. Procedia - Social and Behavioral Sciences, 50(July), 920-927. doi:10.1016/j.sbspro.2012.08.093

Hassan, A., Bakar, A., Razak, A. A., Abdullah, S., Awang, A. \& Perumal, V. (2010). Critical success factors for sustainable housing : A framework from the project. Asian Journal of Management Research, 66-80.

Hui, E. C. M., \& Ho, V. S. M. (2003). Does the planning system affect housing price? Theory and with evidence from Hong Kong. Habitat International, 27, 339-359.

Jiboye, A. D. (2011). Achieving sustainable housing development in Nigeria : A critical challenge to governance, 1(9), 121-127.

Maidin, A. J., \& Ahamed, N. F. S. (2012). Mandatory health impact assessment in Malaysian Land Planning and Development Control System. Procedia - Social and Behavioral Sciences, 68, 164-172. doi:10.1016/j.sbspro.2012.12.216

Md Sakip, S. R., \& Abdullah, A. (2012). An evaluation of Crime Prevention Through Environmental Design (CPTED) measures in a gated residential area: A pilot survey. Asian Journal of Environment-Behaviour Studies, 3(10), 11-24.

Mohd, I., Ahmad, F. \& Wan Abd Aziz, W. A. (2009). Exploiting town planning factors in land development. Journal of Facilities Management, 7(4), 307-318.

Mohd, I., Arbi, E. \& Ramly, A. (2007). Urban housing development: Town Planning issues. Journal of Malaysian Institute of Planner, 43-59. 
Mohd, T. (2011). The role of housing planning practices in contributing towards housing oversupply. World Academy of Science, Engineering and Technology (WASET), 59, 767-775.

Mohit, M. A. (2012). An assessment of policy approaches adopted to deal with Bastee settlement of Dhaka City in Bangladesh. Asian Journal of Environment-Behaviour Studies, 3(9), 1-18.

Othman, A. (2006). Developers' strategies in dealing with planning control: Its impact on the urban housing development. Malaysian Journal of Real Estate, 1(2), 7-15.

Pallant, J. (2010). SPSS survival manual: A step by step guide to data analysis using SPSS. 4th Edition. McGrawHill.

Peerapun, W. (2012). Participatory planning approach to urban conservation and regeneration in Amphawa. Asian Journal of Environment-Behaviour Studies, 3(7), 35-44.

Rameli, A., \& Aman, R. (2011). Ineffectiveness of planning control and its implication to housing oversupply: A case study of. Journal of Civil Engineering and Architecture, 1-15.

Rameli, A., Johar, F., \& Ho, C. S. (2009). The effectiveness of Malaysian Planning System in managing housing supply. Jurnal Alam Bina, 9(2), 1-20.

Sekaran, U. \& Bougie, R. (2009). Research method for business: A skill building approach. John Wiley and Sons.

Shirotsuki, M., Otsuki, S., Sonoda, M. \& Centre, G. E. (2010). Bridging the gap between planning and environmental pyschology: An application of sense of place for visioning of public policy. Asian Journal of Environment-Behaviour Studies, 1(3), 11-23.

Shuid, S. (2010). Low income housing allocation system in Malaysia: managing housing need for the poors. Presented at 22th International Housing Research Conference, 4-7 July, Istanbul.

Wu, J. \& Cho, S. H. (2007). The effect of local land use regulations on urban development in the Western United States. Regional Science and Urban Economics, 37(1), 69-86. doi:10.1016/j.regsciurbeco.2006.06.008

Yakob, H., Yusof, F. \& Hamdan, H. (2012). Land use regulations towards a sustainable urban housing: Klang Valley conurbation. Procedia - Social and Behavioral Sciences, 68, 578-589. doi:10.1016/j.sbspro.2012.12.250

Zainal, N. R., Kaur, G., Ahmad, N. A., \& Mhd, J. (2012). Housing conditions and quality of life of the urban poor in Malaysia. Procedia- Social and Behavioral Sciences, 50, 827-838. doi:10.1016/j.sbspro.2012.08.085 